limitation of the study is that the costs of maintenance and the human resources reengineering required need to be further explored.

Abstract DSL-004 Table 1

\begin{tabular}{|c|c|c|}
\hline & \multicolumn{2}{|c|}{ Advantages and disadvantages of the two systems } \\
\hline & System A & System B \\
\hline \multirow[t]{3}{*}{ SAFETY } & $\begin{array}{l}\text { All DUs can be unequivocally identified } \\
\text { with batch expiry date }\end{array}$ & $\begin{array}{l}\text { Partial identification with batch barcode } \\
\text { and expiry date }\end{array}$ \\
\hline & $\begin{array}{l}\text { Complete record, including batch, } \\
\text { administration by scanner }\end{array}$ & $\begin{array}{l}\text { Record drug administration with bar } \\
\text { code without batch }\end{array}$ \\
\hline & Closed system & Partially open systems, error risks \\
\hline \multirow[t]{4}{*}{ EFFICIENCY } & $\begin{array}{l}\text { Entire integrated system including } \\
\text { outpatients and elderly residences }\end{array}$ & $\begin{array}{l}\text { Immediate availability of nursery doses } \\
\text { needed to the patient }\end{array}$ \\
\hline & Full return of unmanaged DUs & \\
\hline & $\begin{array}{l}\text { Allows automatic checking of expiry } \\
\text { dates }\end{array}$ & Full expiry date control is difficult \\
\hline & High cost & High cost \\
\hline QUALITY & $\begin{array}{l}\text { Complete record of all movements of } \\
\text { both drugs and users }\end{array}$ & $\begin{array}{l}\text { Partial recording of users, batches, } \\
\text { drugs in drug use chain }\end{array}$ \\
\hline $\begin{array}{l}\text { Additional cost } \\
\text { per DU (euros) }\end{array}$ & 0.19 & 0.20 \\
\hline
\end{tabular}

No conflict of interest.

\section{DSL-005 COMPARATIVE STUDY OF THE COST OF ERYTHROPOIETIC FACTORS, ORIGINAL MEDICINES AND BIOSIMILARS IN FRENCH CARE FACILITIES}

doi:10.1136/ejhpharm-2013-000276.248

'D Karouby, 'C Vallet, ${ }^{2} \mathrm{~F}$ Bocquet, ${ }^{3 P}$ Paubel. ' 'GROUPE HOSPITALIER PARIS SAINT JOSEPH, Pharmacy, Paris, France; '2Agence Générale des Produits de Santé, Pharmacy, Paris, France, ${ }^{3}$ Université Paris-Descartes, Pharmacy, Paris, France

Background The patent expiries of leading biological products and the development of biosimilars create opportunities for cost savings. No studies have been carried out in the French hospital market.

Purpose To perform a cost saving modelling analysis and investigate the potential factors that could affect the price of drugs.

Materials and Methods We carried out a comparative study in French healthcare facilities, representing about $65 \%$ of national hospital beds, of the price of erythropoietic factors. The data were collected on procurement procedures operative as of 1 January 2012.

Results 25 care facilities agreed to participate in the study. The overall sales turnover reached $€ 15 \mathrm{M}$. Biosimilars represent less than $1 \%$ market share. All the establishments granted a discount of between $5 \%$ and $69 \%$ on the prices fixed by negotiation between the Comité Economique des Produits de Santé and the manufacturers, depending on the category (drugs, biosimilars or original biopharmaceuticals). The average discounts ranged from $11 \%$ to $73 \%$. Binocrit, the main biosimilar represented was $25.6 \%$ less expensive than its original medicine Eprex. Based on French hospital financing, we show a $24.7 \%$ cost saving if a high interchangeability rate is adopted. Some participants could save up to $50 \%$ of their budget.

We identified and analysed three criteria known to have a farreaching effect on the drugs price. We observe no or little effect of the type of procurement procedure and specified quantity of medicine. The starting date of the contract is the primary criterion when purchasing drugs. The impact of these criteria varied depending on the drug in question and no general conclusions about medicines could be drawn.

Conclusions The market for biosimilars is growing at a faster rate than the global prescription-drug market. Many top-selling biologicals are due to lose patent protection over the next few years. The great potential for cost savings apparent in our study could be investigated in other countries.

No conflict of interest.

\section{DSL-006 COST ANALYSIS OF ADULT PARENTERAL NUTRITION SYSTEMS: THREE-COMPARTMENT BAG VERSUS CUSTOMISED}

doi:10.1136/ejhpharm-2013-000276.249

'D Berlana, 'P Sabin, ${ }^{2} \mathrm{~J}$ Rius, ${ }^{2} \mathrm{E}$ Llop, ${ }^{3} \mathrm{R}$ Romero, 'E Marquez, ${ }^{2} \mathrm{JA}$ Schoenenberger, 1J Martinez. 'Hospital Univ. Vall Hebron, Pharmacy, Barcelona, Spain; ${ }^{2}$ Hospital Arnau Vilanova, Pharmacy, Lleida, Spain; ${ }^{3}$ Hospital Gregorio Marañon, Pharmacy, Madrid, Spain

Background Parenteral nutrition (PN) is a costly technology used widely to provide nutrition to patients who have an inaccessible or non-functioning intestine. Two all-in-one systems currently being used are customised formulations, prepared by hospital pharmacies, and three-compartment bags.

Purpose To provide a systematic cost comparison of the two all-inone PN systems: individualised (made from nutrient solutions) versus manufactured (made from three-compartment bag), both prepared in hospital pharmacies.

Materials and Methods We conducted a prospective study to analyse the total cost of PN bags, accounting for all of the processes involved in preparing and delivering them (the cost of manpower, nutrition solutions, medical supplies and quality controls) in three different healthcare settings. To compare therapeutic alternatives of equivalent nutritional value, the study was performed for the most frequently-employed formulation, which was similar to commercial preparations. A univariate sensitivity analysis was performed to evaluate the impact of different rates of use of three-compartment PN bags.

Results 157 routine acts of PN bag preparation (65 hospital compounded and 92 three-compartment) were observed and timed over 9 days. Total costs of the 157 PN bags were included in the study. Mean costs of hospital-compounded bags were higher than threecompartment bags, $51.16 \pm 5.63 €$ versus $39.69 \pm 3.00 €$ respectively $(p<0.01)$. Manpower costs were responsible for the majority of the differences found (70\%). In scenarios using a three-compartment system for $30 \%, 70 \%$ and $90 \%$ of $\mathrm{PN}$ provision, a cost savings of $4.3 \%, 10.1 \%$ and $12.9 \%$ respectively could be achieved. Greatest rates of changing from hospital compounded bags (70\% and $90 \%)$, in a hospital with 1,800 PN bags/year, might reduce the annual budget by $9306 €$ and $11,964.8 €$, respectively. Meanwhile, in a large facility the savings for 8,000 TPN days would be $64,248 €$ and $82,605 €$, respectively.

Conclusions Since we need to reduce the costs of effective treatments, three-compartment bags could be used for standard adult PN to save money.

No conflict of interest.

\section{DSL-007 DOES PHARMACY CONTRIBUTE TO DELAYS IN HOSPITAL DISCHARGE?}

doi:10.1136/ejhpharm-2013-000276.250

V Marvin, S Kuo, D Linnard. Chelsea and Westminster Hospital, Pharmacy Dept, London, UK

Background Efficient management of patient flow including timely discharge from hospitals is vital. Patients in UK hospitals are commonly given individually labelled medicines to take home (TTOs). It is perceived by the multidisciplinary team at our hospital that waiting for these medicines is a significant rate-limiting step in the discharge process.

Purpose We examined the timeframes around TTO prescribing, dispensing and patient discharge in order to identify delays and any negative impact of the pharmacy processes involved.

Materials and Methods All TTO prescriptions entered into the pharmacy electronic log on one day in May 2012 were examined 
retrospectively. Once dispensed, TTOs are logged 'off' and sent by pneumatic chute system direct to the ward. This log and the hospital electronic prescribing system store relevant data including the time a TTO is written, dispensed and the patient discharged.

Results A total of 65 TTOs were dispensed in the pharmacy. (Others are prepared in a satellite unit, not included in this study). Only 18\% were prescribed more than 24 hours before discharge. Writing of TTOs clustered around $11 \mathrm{am}-4 \mathrm{pm}$ whereas patient discharges were around $12-1 \mathrm{pm}$ and $2-6 \mathrm{pm}$. Nearly $90 \%$ of TTOs were ready within 2 hours of the prescription being written. The average time from writing a TTO to the patient's discharge was 2.5 hours. The average dispensing time per patient was 1.2 hours. The Pharmacy element accounted for less than half the time patients were waiting for TTOs.

Conclusions The perception that dispensing of TTOs is responsible for significant delays in patient discharge is unfounded. There is a lag time between TTOs being ready and the patient going home which merits further investigation. The clustering of TTO writing infers that very few are written until the morning ward rounds are finished. Options are being explored to encourage earlier writing times such as including TTO-transcribing pharmacists on consultants' rounds.

No conflict of interest.

\section{DSL-008 DRUG SHORTAGES IN THE NETHERLANDS: MONITORED BY FARMANCO}

doi:10.1136/ejhpharm-2013-000276.251

DJ Postma, LM de Wolf. Royal Dutch Pharmacists Association, Scientific Institute for Dutch Pharmacists, Den Haag, The Netherlands

Background Internationally, drug shortages cause increasing concern. For patients it may impose a significant effect on their safe use of medicines. For pharmacists it is time-consuming to get trustworthy information.

Purpose With a central approach on the investigation of drug shortages, pharmacists get reliable and up-to-date information. Besides, solutions can be suggested. If there is a shortage of a necessary drug, proper action can be taken by all pharmacies.

With the data, trends in drug shortages can be signalled.

Materials and Methods In 2004 the Royal Dutch Pharmacists Association (KNMP) launched the website Farmanco: www. farmanco.knmp.nl. It provides pharmacists with up-to-date information on drug shortages in The Netherlands. Drug shortages are reported early and proper action can be taken. It provides information about the cause and duration of the shortage and a possible solution such as substitution or a pharmaceutical alternative.

Farmanco data from 2004 till 2011 were analysed to get an overview of the scale of the problem and more insight into the causes and solutions.

Results Through the years, the Farmanco website has become relevant to all concerned parties for up-to-date information. Visits to the website have increased to about 600 visitors on a weekday.

From 2004 till 2011 the Farmanco website published information on more than 1400 products.

Drug shortages have increased in frequency from 91 reported shortages in 2004 up to 242 in 2011.

The duration of a shortage has increased from 139 days (2004) to 254 days (2010).

Temporarily shortages are mainly caused by production problems $(52 \%)$, whereas permanent shortages usually have an economic reason $(69 \%)$.

The solutions have mainly been substitution (62\%), a pharmaceutical alternative $(25 \%)$ or pharmaceutical compounding $(2 \%)$. In $1 \%$ of the cases a solution was impossible.
Conclusions Farmanco gives pharmacists up-to-date information on drug shortages in The Netherlands.

Finally, trends in drug shortages can be signalled.

No conflict of interest.

\section{DSL-009 DRUG SHORTAGES: THE CHALLENGE OF IMPORTING}

doi:10.1136/ejhpharm-2013-000276.252

C Sousa. Hospital de Faro E.P.E. , Pharmacy, Faro, Portugal

Background Drug shortage has been reported since several years but has recently reached critical levels. Shortage occurs not only in Europe but worldwide, in all healthcare practise settings and affects potentially all drug classes, raw materials and medical devices. This combination of factors leads undoubtedly to medication overpricing and higher costs to the healthcare system, suboptimal clinical care, more medication errors and adverse events and the loss of patients' lives. Rational and effective procurement of medicines in foreign countries can be a challenge for hospital pharmacists.

Purpose The objective is to present a framework on medicines importation, with a special focus on European countries.

Materials and Methods Web search on governmental healthcare institutions (i.e. medicines' agencies), wholesalers, manufactures and other legal suppliers. This work was designed considering the Portuguese drug shortage.

Results A standard operation methodology was designed for searching for new suppliers for special medicines, not marketed or sold out. Search methodology on medicines' agencies is presented. A short framework for suppliers was filled considering regulatory issues, current good manufacturing practises, place in the drug supply chain, logistics, packaging, pricing, taxes, expedition costs and payment conditions. Web links to suppliers' websites are included. Conclusions Importation of medicines at the hospital level is more often part of the daily tasks of pharmacists. When treating critical health conditions, shortages in essential medicines can cause disruptions in patients' safety and quality of pharmacological treatment.

No conflict of interest.

\section{DSL-010 ECONOMIC IMPACT OF AUTOMATED DRUG DISPENSING SYSTEMS IMPLEMENTATION}

doi:10.1136/ejhpharm-2013-000276.253

A Linares-Alarcon, A Luna-Higuera, M Toca-Muñoz, MA Rosado Souviron, IM MuñozCastillo. HRU Carlos Haya, Pharmacy, Malaga, Spain

Background The distribution, management and control of drug stocks in clinical units is a responsibility of the pharmacy department, but this control is difficult to perform manually, resulting in a loss of important information about drug use.

Purpose To analyse the economic impact of automated drug dispensing systems (ADSs) implemented in the Intensive Care Unit (ICU) and the emergency department (ED).

Materials and Methods A total of 5 Omnicell cabinets were installed in August 2008: 3 in ICU and 2 in ED. The average cost of implementation for each one was about 60,000 euros. Nevertheless, the Hospital did not have to invest in them since they were donated by a national foundation.

The ICU is comprised of a total of 42 dedicated critical care beds located in 3 different modules, and ED has 2 modules with a total of 22 beds and 9 chairs.

The ADSs are connected to hospital admission software and to the pharmacy management software.

Medication costs in ICU and ED were examined, comparing one year prior to installation with the years after implantation of the ADS. These data were obtained from the management software of the pharmacy department. 